\title{
Michael Schuenke, Erik Schulte, Udo Schumacher, Laurence M. Ross, Edward D. Lamperti: THIEME Atlas of anatomy neck and internal organs
}

\author{
Georg Thieme Verlag, Stuttgart, New York, 2006, 344 pp., 962 illustrations, \\ 78 tables Softcover 49,95 CHF 82,00, ISBN 13: 978-1-58890-443-0 (TNY), \\ ISBN 13: 978-3 13 142091-6 (GTV)
}

\section{Pierre Kehr}

Received: 16 August 2009 / Accepted: 18 August 2009 / Published online: 1 September 2009

(C) Springer-Verlag 2009

This atlas of anatomy is a hard copy of the beautiful DVD* by the same authors. The beautifully coloured drawings and attention to details make this hard copy version stand out.

This book of anatomy is a genuine work of art; drawings, integrating the most recent advances in medical imaging, are magnificent and perfectly legible. An outline of the different planes is provided for the majority of anatomical drawings using a colour code. Highly detailed studies of visceral anatomy are accompanied by explanations often complemented by embryo drawings. The final third of the book covers the innervation and vascularization of the organs, and is intended for both students and surgeons. A very detailed index is also included, enabling easy access to the items.

It is recommended to students and scholars who wish to apply anatomical facts to clinical practice.

No funds were received in support of this study.

Pierre Kehr Strasbourg

P. Kehr $(\square)$

Strasbourg, France

e-mail: kehrpier@aol.com 